\title{
Saúde Mental e Infância: Reflexões Sobre a Demanda Escolar de um CAPSi
}

Mental Health And Childhood: Reflexions On The School Demand Of A CAPSi

Salud Mental E Infancia: Reflexiones Sobre La Demanda Escolar De Un CAPSi

Marina Maria Beltrame \& Maria Lúcia Boarini

Universidade Estadual de Maringá
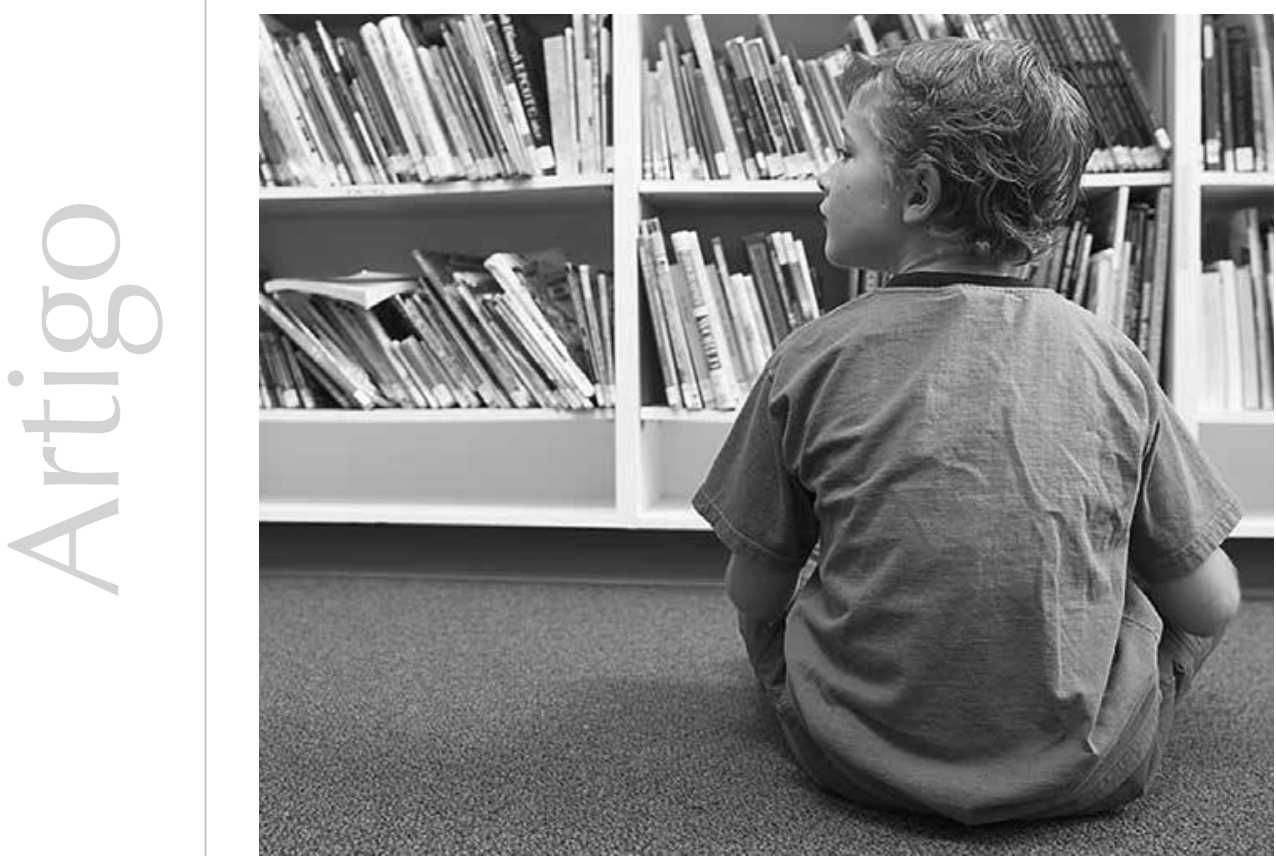
Resumo: Este artigo é resultado de um estudo exploratório desenvolvido entre o segundo semestre de 2008 e em 2009, cujo objetivo consistiu em analisar a demanda escolar encaminhada, acolhida e atendida pelo Centro de Atenção Psicossocial Infanto-Juvenil - CAPSi - de um Município do Estado do Paraná. Como recurso metodológico, adotamos a pesquisa de campo, que foi realizada em três fases subsequentes. A primeira consistiu em um levantamento estatístico acerca de todos os prontuários dos pacientes acolhidos pelo CAPSi estudado entre os meses de julho e dezembro de 2008. Na segunda, a partir dos prontuários examinados na primeira fase, realizamos o estudo de seis casos de crianças que envolviam queixas escolares, e a terceira correspondeu às entrevistas realizadas com cinco funcionários do dispositivo. Os resultados apontaram o atendimento de um número expressivo de casos referentes a queixas escolares que, em geral, eram tratados via medicação. Tal panorama encontra respaldo na dinâmica de trabalho do dispositivo, que revelou dificuldades em desenvolver um trabalho intersetorial. As decisões pertinentes ao serviço desse CAPSi são, em geral, capitaneadas pelo médico e destituídas de questionamentos por parte dos demais integrantes da equipe, evidenciando quão naturalizada e quão distante essa prática está dos princípios preconizados pela Política Nacional de Saúde Mental.

Palavras-chave: Saúde mental. Serviços de saúde mental. Distúrbios da aprendizagem. Educação. Medicalização. Centro de Atenção Psicossocial - CAPS.

Abstract: This paper is the result from an exploratory study developed between the second half of 2008 and 2009, whose goal consisted in analyzing the school demand referred, accepted and assisted by the Center for Psychosocial Care of Children and Adolescents - CAPSi - in a town in Paraná. As a methodological resource, we adopted a field research, conducted in three subsequent stages. The first stage consisted of a statistical assessment of all medical records from the users assisted at the CAPSi between July and December 2008. Next, from the medical records examined in the first stage, we studied six cases of children involving school complaints. The third and final phase consisted of interviews with five workers at the center. The results pointed the attendance of a significant number of cases involving school complaints that were generally treated via medication. Such scenario is supported by the work dynamics, which revealed difficulties in developing an intersectoral work. The decisions pertaining to the service of this CAPSi are usually headed by the doctor, without questionings from the other team members, what demonstrates how naturalized and how far this practice is from the principles advocated by the National Policy on Mental Health.

Keywords: Mental health. Mental health services. Learning disabilities. Education. Medicalization. Psychosocial Care Center.

Resumen: Este artículo es el resultado de un estudio exploratorio desarrollado entre el segundo semestre de 2008 y en 2009, cuyo objetivo consistió en analizar la demanda escolar encaminada, acogida y atendida por el Centro de Atención Psicosocial Infanto-Juvenil - CAPSi - de un Municipio del Estado de Paraná. Como recurso metodológico, adoptamos la investigación de campo, que fue realizada en tres etapas subsiguientes. La primera consistió en un relevamiento estadístico acerca de todas las historias clínicas de los pacientes recolectados por el CAPSi estudiadas entre los meses de julio y diciembre de 2008. En la segunda, a partir de las historias clínicas examinadas en la primera etapa, realizamos el estudio de seis casos de niños que involucraban quejas escolares, y la tercera correspondió a las entrevistas realizadas con cinco empleados del dispositivo. Los resultados señalaron la atención de un número expresivo de casos referentes a quejas escolares que, en general, eran tratados vía medicación. Tal panorama encuentra respaldo en la dinámica de trabajo del dispositivo, que reveló dificultades en desarrollar un trabajo intersectorial. Las decisiones pertinentes al servicio de ese CAPSi son, en general, capitaneadas por el médico y destituidas de cuestionamientos por parte de los demás integrantes del equipo, evidenciando lo naturalizada y lo distante que esa práctica está de los principios preconizados por la Política Nacional de Salud Mental.

Palabras clave: Salud mental. Servicios de salud mental. Transtorno del aprendizaje. Educación. Medicalización. Centro de Atención Psicosocial - CAPS.

No que tange à incidência de transtornos mentais entre crianças e adolescentes, dados epidemiológicos revelam, em todo o mundo, uma prevalência na faixa de 10 a $20 \%$, dos quais, entre 3 e $4 \%$, há indicação de cuidados intensivos (Brasil, 2005). Embora esses números revelem que os transtornos mentais acometem não só adultos mas também crianças e adolescentes, ressaltamos, outrossim, que estão incluídos nesses números muitos diagnósticos de transtornos questionáveis quanto a sua etimologia como doença. Nas palavras de Guarido (2010, p. 29).

Levando em conta as crianças, tem se produzido, atualmente, uma multiplicidade de diagnósticos psicopatológicos e de terapêuticas que tendem a simplificar as 


\begin{abstract}
1Nesse período, surgiram relatos sobre os primeiros ensaios de reabilitação de crianças e adolescentes acometidos por alguma deficiência.

determinações dos sofrimentos ocorridos na infância. O que reconhecemos como resultado desse tipo de prática é que um número cada vez maior de crianças em idade cada vez mais precoce é medicado de forma a sanar os sintomas das crianças, sem considerar o contexto no qual se apresentam
\end{abstract}

No século XVI,

Ponce de Leon, padre beneditino, iniciou as primeiras tentativas de educação de surdos-mudos

(Ajuriaguerra, 1980).

Mais tarde, em

1797, na França,

sob os cuidados

do médico Jean

Itard (1774-1838), realizou-se a

primeira experiência com o intuito de reabilitar um adolescente com retardo mental (Alexander \& Selesnick, 1980).

2 Movimento consolidado no Brasil a partir de 1923, com a criação da Liga Brasileira de Higiene Mental - LBHM suas intervenções visavam, sobretudo, à prevenção das

"doenças nervosas e mentais" (Liga Brasileira de Higiene Mental, 1930, p.71).

3Dirigida por Mirandolino Caldas, essa clínica visava a "assegurar a boa formação do psiquismo" (Caldas, 1932, p.31), por meio de intervenções médicas e pedagógicas dirigidas às crianças.

4 No Rio de Janeiro, eram dirigidas pelo médico higienista Arthur Ramos

(1903-1949); em São Paulo, pelo

Em que pese à legitimidade desse debate em torno dos diagnósticos que envolvem as problemáticas infantis, não podemos negar a existência de transtornos mentais entre o público infanto-juvenil e a necessidade de projetos de assistência nessa área. Sobre isso, Delgado et al. afirmam que, no Brasil, "é histórica a omissão da saúde pública no direcionamento das políticas de saúde mental para a infância e a adolescência" (2007, p. 66). Essa, porém, é uma omissão que não se restringe ao Brasil, conforme nos revela o Relatório sobre a Saúde no Mundo, divulgado pela Organização Pan-Americana de Saúde e Organização Mundial de Saúde, em 2001, cujos dados apontam que mais de $90 \%$ dos países não possuíam, até aquele momento, políticas de saúde mental que incluíssem crianças e adolescentes.

No decorrer da História, observamos que as primeiras experiências voltadas para o cuidado à criança considerada anormal datam do século $X V{ }^{1}$. Contudo, foi no século XX, em um contexto marcado pela crescente industrialização, pelas altas taxas de mortalidade infantil e pela necessidade de mão de obra, que as ações em prol da infância foram intensificadas em vários países, inclusive no Brasil.

Em nosso país, a assistência à criança caracterizou-se pelo cuidado prestado por instituições de caridade, filantrópicas e privadas, tais como abrigos ou asilos para menores abandonados e colégios destinados ao amparo dessa população. Nesse processo, foi marcante para o País a atuação do Movimento de Higiene Mental ${ }^{2}$, cujos idealizadores, entre o final do século XIX e o início do século XX, empenharam-se na realização de campanhas e de projetos que visavam a solucionar os seus problemas sociais, preparando o futuro homem e, em consequência, uma nova pátria por meio de ações direcionadas à higiene física e mental da população, em especial do público infantil.

Na obra do higienista Moncorvo Filho (1927), intitulada Histórico da Protecção à Infância no Brasil, encontramos importantes referências a estabelecimentos e práticas com o intuito de amparar a criança. Dentre eles, destacamos as Rodas dos Expostos, cuja prática perdurou do século XVIII até meados do século XX, o Instituto de Protecção e Assistência à Infância - IPAI, inaugurado na cidade do Rio de Janeiro, em 1899, e a criação de alas específicas para o tratamento do público infantil nos manicômios, como, por exemplo, o Pavilhão-Escola Bourneville, criado em 1903, no Hospital Nacional de Alienados no Rio de Janeiro, e a Seção de Menores Anormais do Hospital Central de Juqueri, em 1922, em São Paulo.

Outras iniciativas idealizadas e concretizadas nesse período enfocavam a prevenção da criança contra o acometimento de possíveis doenças mentais. A título de exemplo, citamos o trabalho desenvolvido pela Clínica de Euphrenia ${ }^{3}$, inaugurada na cidade do Rio de Janeiro, em 1932, e as Clínicas de Orientação Infantil ${ }^{4}$, instaladas em escolas públicas das cidades do Rio de Janeiro e São Paulo em 1934 e 1938, respectivamente.

Enfim, dando um salto na História, atualmente, a estratégia de cuidado a crianças e adolescentes portadores de transtornos mentais, preconizada pela OMS e adotada por alguns países, baseia-se no modelo comunitário, realizado por equipes multiprofissionais. O Brasil, seguindo essa mesma tendência, vivencia o processo de construção de uma rede comunitária de 
médico Durval Marcondes (1899-1981). Em ambas as cidades, as clínicas caracterizavamse pelo enfoque multiprofissional e tinham o objetivo de identificar e de corrigir precocemente as condutas infantis consideradas sinais de desadaptação psíquica

(Marcondes, 1941; Mendonça, 2006).

\footnotetext{
5 Ressalvamos que a partir da Portaria no 3088, de 23 de dezembro de 2011, foi incluído como atribuição dos CAPS, em todas as suas modalidades, $\mathrm{o}$ atendimento às pessoas com necessidades decorrentes do uso de álcool e outras drogas.
}

cuidados, na qual os Centros de Atenção Psicossociais (CAPS) devem ocupar um papel estratégico no tratamento às pessoas com transtornos mentais severos. No que tange à infância, essa modalidade de serviço vem sendo discutida desde a I Conferência de Saúde Mental, realizada em Brasília, em 1987 (Brasil, 1988), todavia, somente em 2001, na III Conferência de Saúde Mental (Brasil, 2002a), encontramos uma alusão direta ao dispositivo CAPSi - Centro de Atenção Psicossocial Infanto-Juvenil, definido pelo Ministério da Saúde como:

um serviço de atenção diária destinado ao atendimento de crianças e adolescentes gravemente comprometidos psiquicamente. Estão incluídos nessa categoria os portadores de autismo, psicoses, neuroses graves (itálicos nossos) e todos aqueles que, por sua condição psíquica, estão impossibilitados de manter ou estabelecer laços sociais (Brasil, 2004, p. 23) ${ }^{5}$

Essa definição deixa claro qual deve ser a função de um CAPSi. Mas se, por um lado, a existência de transtornos mentais na infância justifica a criação do CAPSi, cuja finalidade é a de prestar assistência a essa população, por outro, observamos uma demanda que, em geral, não se caracteriza como tal. Enunciamos essa afirmação embasadas em um levantamento referente à clientela atendida pelo CAPSi de um Município localizado no interior do Estado do Paraná, o qual tomamos como objeto deste estudo. Os dados do levantamento, realizado entre julho e dezembro de 2008, apontaram que a demanda que envolvia problemas escolares representou cerca de $60 \%$ dos acolhimentos. Tal constatação nos fez questionar se todos os casos de crianças e adolescentes encaminhados a esse dispositivo por problemas escolares corresponderiam àqueles definidos pelo Ministério da Saúde citados anteriormente.

A fim de explorar essa problemática, propomos, neste estudo, analisar a demanda escolar encaminhada, acolhida e atendida pelo CAPSi supracitado. Especificamente, objetivamos compreender os motivos envolvidos em tais encaminhamentos, e, uma vez acolhidos pelo serviço, verificar como se caracterizavam o atendimento e o tratamento ofertados a esses usuários. Sem a pretensão de esgotar o assunto, acreditamos que os resultados obtidos possam oferecer subsídios para uma reflexão acerca dos avanços e dos entraves que perpassam a construção da atual Política Nacional de Saúde Mental voltada para o público infanto-juvenil.

\section{Metodologia}

Este estudo foi desenvolvido entre os anos 2008 e 2009, sendo os dados que subsidiam esta discussão referentes ao segundo semestre de 2008. Considerado como um dispositivo recente dentro das políticas públicas de saúde mental do Brasil, o CAPSi é, por tal motivo, um tema ainda pouco debatido; dessa forma, podemos caracterizar este estudo como uma pesquisa exploratória.

A fim de concretizar o objetivo proposto, empregamos como recurso metodológico a pesquisa de campo, que, de acordo com Minayo (1996), possibilita o encontro direto do investigador com seu objeto de estudo. No presente estudo, a pesquisa de campo ocorreu em três fases, conforme apresentamos a seguir.

\section{Primeira fase}

Esta etapa consistiu em um estudo quantitativo. Inicialmente, realizamos uma consulta a todos os prontuários dos usuários acolhidos pelo CAPSi estudado no período compreendido entre julho e dezembro de 2008. Optamos por coletar dados referentes a esse período porque, no mês de junho do mesmo ano, em reunião que visava a capacitar os órgãos públicos do Município vinculados ao cuidado 
infanto-juvenil, como as escolas e o Conselho Tutelar, foram prestados esclarecimentos e informações sobre o funcionamento e o público a ser atendido pelo CAPSi.

No total, examinamos 193 prontuários, por meio dos quais foi possível verificar as características da clientela, tais como idade, gênero, queixa, procedência do encaminhamento e diagnóstico.

\section{Segunda fase}

A fim de compreender as razões dos encaminhamentos e posterior acolhimento pelo CAPSi, optamos pela realização de estudos de caso. Para realizar o recorte que gerou os casos aqui estudados, utilizamos os mesmos prontuários examinados na primeira fase.

A escolha dos casos ocorreu de forma aleatória. Com o objetivo de facilitar o trabalho do pesquisador e do pesquisado, aproveitamos a ida dos usuários agendados ao CAPSi para entrevistá-los. Por meio do exame prévio das consultas agendadas com profissionais do CAPSi, verificamos, de acordo com o número do prontuário, quais casos correspondiam ao período investigado na primeira fase da coleta de dados. Quando a família chegava para o atendimento, fazíamos a abordagem, e, uma vez confirmada que a queixa era de ordem escolar, solicitávamos a participação na pesquisa. Como técnica para coleta de dados, utilizamos a entrevista semidirigida.

Após esse processo, as entrevistas com os familiares dos usuários foram realizadas até que o assunto se mostrasse saturado, o que, a nosso ver, ocorreu a partir do sexto caso. Além das famílias, fizeram parte da população
Município, responsável pela avaliação e pelo acompanhamento dos alunos do 1 음 5 음 ano, com os quais foram realizadas entrevistas a partir de um roteiro previamente elaborado.

Findado o processo de realização das entrevistas, continuamos a coleta de dados por meio do exame dos prontuários, dos relatórios escolares e de outros documentos relacionados aos seis casos investigados. Salientamos que, nesta etapa, os dados referentes ao atendimento prestado pelo CAPSi e, por conseguinte, à conduta médica concernente a cada caso, foram obtidos via prontuário.

\section{Terceira fase}

Nesta etapa, empreendemos a realização de entrevistas semidirigidas com cinco profissionais do CAPSi, a saber: uma psiquiatra, uma neuropediatra, uma assistente social, uma psicóloga e uma enfermeira que também exercia o cargo de coordenadora do serviço. Após serem informadas sobre o teor da pesquisa, as participantes foram entrevistadas separadamente na própria instituição. Todas as entrevistas, inclusive as da segunda fase, foram audiogravadas.

\section{Resultados e discussão}

Na apresentação dos resultados, optamos por expor os dados quantitativos de forma cursiva. Ao discutir os dados qualitativos, utilizamos como recurso ilustrativo alguns trechos relatados pelos participantes da pesquisa, além do conteúdo de relatórios escolares e dos prontuários dos casos estudados. Ressalvamos que todos os nomes citados são fictícios. Como os dados foram obtidos, sobretudo, por meio de informações orais, privilegiamos sua compreensão considerando, assim como Moro, Lecuona e Álvarez (1985), que uma das características dessa fonte de informação consiste na capacidade de refletir a sociedade concreta. Destarte, mais 
do que evidenciar acontecimentos locais ou experiências de vida, os relatos das pessoas envolvidas no cotidiano do CAPSi estudado expressam a sociedade que os produz.

Subdividimos este item em quatro tópicos: Alguns números, Da escola ao CAPSi: a busca pela medicação, No CAPSi: percalços na consolidação do trabalho coletivo e $O$ controle social. Os dois primeiros referemse respectivamente à apresentação dos resultados e à discussão da primeira e da segunda fases da pesquisa, e os dois últimos, à terceira fase.

\section{Alguns números...}

Os dados obtidos após a realização da primeira fase da pesquisa mostraram que, de um total de 193 prontuários examinados, $68 \%$ dos acolhimentos referiram-se a usuários do sexo masculino. Em 43,52\% dos casos, a faixa etária concentrou-se entre seis e dez anos de idade, $31,60 \%$ corresponderam à faixa etária dos onze aos quatorze anos, $19,68 \%$ entre os quinze e os dezessete anos e $5,18 \%$ foram referentes a faixa etária dos três aos cinco anos.

Com relação às queixas, separamo-las em três itens: queixa escolar referente àqueles casos em que o problema se relaciona apenas à dificuldade de aprendizagem e ao comportamento na escola, queixa escolar associada a outros sintomas, que englobam os casos nos quais, além da queixa escolar propriamente dita, estão presentes sintomas de outra ordem, e outras queixas para designar os casos não relacionados a questões escolares. Nesses termos, constatamos que a queixa específica relativa a problemas de aprendizagem e a comportamento na escola, que totalizou 54 casos, representou um percentual em torno de $28 \%$. Se considerarmos essas queixas somadas àquelas em que houve uma associação entre queixas escolares e outros sintomas, cujo índice atingiu 63 casos, o total de casos que envolvem queixas escolares sobe para 117, ou seja, cerca de $60 \%$ dos encaminhamentos. O alto número de casos relacionados a problemas escolares coincide com o fato de a escola ter sido apontada como a principal responsável pelos encaminhamentos ao CAPSi, perfazendo $37,3 \%$ do total da demanda encaminhada ao serviço no período investigado.

Outros dados levantados dizem respeito ao diagnóstico. Tal como constava nos prontuários, utilizamos as divisões adotadas pela Classificação Internacional de Doenças - CID-10 (Organização Mundial da Saúde, 1993). Os maiores índices registrados concentraram-se nos casos referentes a transtornos do comportamento e a transtornos emocionais que aparecem habitualmente durante a infância e a adolescência, classificação que engloba o transtorno de déficit de atenção, a hiperatividade - TDAH - e o distúrbio de conduta, que totalizaram 44 casos, e os transtornos do humor, com 36 registros. Destacamos, em contrapartida, que os casos referentes à esquizofrenia somaram quatro, e os concernentes ao transtorno do desenvolvimento psicológico, que abarcam, dentre outros quadros psicopatológicos, o autismo, nenhum.

\section{Da escola ao CAPSi: a busca pela medicação}

Os casos estudados revelaram que, em geral, os encaminhamentos dos alunos ao CAPSi foram motivados por problemas relacionados à aprendizagem e ao comportamento na escola, como ilustram os excertos: - $O$ aluno é desatento, desinteressado, não cuida do material, não faz a tarefa de sala de aula, é briguento, gosta de provocar os amigos, não obedece às normas da escola (relatório escolar sobre André, 7 anos, 2 응 ano). - $O$ aluno apresenta aproveitamento 
7 Com a implantação do ensino fundamental de nove anos, a nomenclatura atual utilizada para essa etapa seria 6 o ano. Todavia, como no período de realização deste estudo alguns alunos participantes da pesquisa iniciaram a vida escolar quando o ensino fundamental ainda contava com oito anos de duração, optou-se, nesses casos, por manter a nomenclatura da época.

8 Os dados revelam, por exemplo, um alto índice de repetência $(18,7 \%)$ e baixos índices de conclusão da educação básica.

Considerando as metas sobre $\mathrm{o}$ acesso e qualidade do ensino, o Brasil ocupa a $88^{-}$ posição entre 128 países (UNESCO, 2010). escolar muito abaixo da média e também está fora da faixa etária para a série que está cursando. É extremamente indisciplinado, irrequieto, provoca os colegas o tempo todo, fala palavrões e é muito agressivo em suas respostas e no trato com todos (relatório escolar sobre Mateus, 14 anos, $5^{\mathfrak{a}}$ série $^{7}$ ).

Segundo os relatos dos entrevistados, tais encaminhamentos ocorrem quando, supostamente, esgota-se, dentro do contexto escolar, a gama de possibilidades em lidar com as dificuldades desses alunos. Assim, o fato de os objetivos da instituição escolar não alcançarem êxito acaba justificando a busca por parcerias em outros setores, como o CAPSi; todavia, o repensar das práticas escolares não é considerado nesse processo.

Dados divulgados em 2010 pela Organização das Nações Unidas para a Educação, a Ciência e a Cultura (UNESCO) mostram que a rede de ensino do País ainda apresenta inúmeras dificuldades ${ }^{8}$. Poderíamos ilustrar esse panorama com várias notícias veiculadas pela mídia recentemente. No entanto, a título de exemplo, citamos as problemáticas observadas e mencionadas pelos próprios entrevistados ouvidos nesta pesquisa. A rotatividade de professores, alunos encaminhados à fonoaudióloga para serem alfabetizados e alunos que chegam ao $6^{\mathrm{o}}$ ano sem dominar as operações matemáticas básicas foram algumas das situações lembradas. Como se não fossem suficientes esses problemas de ordem pedagógica, os depoimentos desvelaram outro agravante a que estão sendo expostos alguns desses alunos: a violência física e a exclusão fomentada pelos próprios educadores: - Ela (professora) acho que não tinha paciência. Chamava ele de burro, rasgou uma folha do caderno dele e 'socou' na boca dele, puxava o cabelo... ichi (Neide, mãe de Luiz, 11 anos, 5 a série).

Assim, embora geradas nas e pelas relações estabelecidas no contexto escolar, os alunos cujos comportamentos são considerados inadequados às normas e aos objetivos da instituição, na busca de soluções para essas situações, são apartados do contexto em que foram engendrados. "O indivíduo particular é quase sempre responsabilizado pelas tensões e conflitos existentes" (Boarini, 1998, p.15), e, com base nesse princípio, as medidas adotadas pela escola procuram sanar ou minimizar a agressividade ou a inquietação apresentada pela criança, acreditando que isso possa favorecer o cumprimento das metas educacionais.

Como demonstrou Patto em seus estudos $(1985,1997)$, a Psicologia, na década de 80 , sobretudo por meio dos testes psicológicos, cumpriu a função de responder aos anseios dos profissionais da educação ao encaminhar alunos que apresentavam dificuldades escolares, qual seja, a de identificar alguma anormalidade que justificasse tais dificuldades. Dos seis casos estudados, quatro foram encaminhados ao CAPSi com o aval de psicólogos, evidenciando que, ainda hoje, esses profissionais têm participação nos encaminhamentos de alunos para tratamentos especializados. Todavia, como destacam Boarini e Borges, "só o especialista já não basta" (2009, p. 124). Embora a participação da Psicologia nesse processo ainda tenha relevância, percebemos, na atualidade, que a fórmula mágica encontrada, em geral pelos professores e por alguns profissionais da área da Psicologia, é a medicação, conforme observamos no relato abaixo:

Mas ele é um caso que, quando você falou da medicação, eu estava lembrando dele, porque a família estava deixando de dar a medicação, foi, assim, visível a mudança. Ele tomava medicamento, daí a família parou, e aí a família não levou na consulta que estava marcada, parece, deixou de dar o medicamento, então, ele voltou a ter problemas. Ele estava até avançando, mas voltou a ter problemas (psicóloga da Saúde do Escolar, sobre André). 
9 De acordo com a Portaria SAS/MS no 224 , de 29 de janeiro de 1992, o atendimento em nível ambulatorial "compreende um conjunto diversificado de atividades desenvolvidas nas Unidades Básicas/ Centros de Saúde e/ou ambulatórios especializados"

(Brasil, 1992, p.1) que deve ser realizado por uma equipe multiprofissional. Sobre essa forma de assistência, dados divulgados pelo Ministério da

Saúde (Brasil, 2007a) apontam que as intervenções dos ambulatórios de saúde mental, em sua grande maioria, apresentamse pouco articuladas com a rede de

atenção. Outro ponto destacado foi uma

baixa resolutividade desse dispositivo, considerado

referência, sobretudo, para consultas psiquiátricas e psicológicas. Já os CAPS são definidos pela Portaria no 336/ $\mathrm{GM}$, de fevereiro de

2002, como serviços de saúde mental de base territorial e comunitária do SUS, referenciais no tratamento de pessoas portadoras de transtornos mentais severos. As atividades, que devem ser desenvolvidas por equipes multiprofissionais, visam ao atendimento clínico e à reinserção social dos usuários (Brasil, 2002b).
O medicamento vem sendo uma das alternativas utilizadas no tratamento de muitas crianças encaminhadas ao CAPSi devido a queixas relacionadas a questões escolares. Parte-se da ideia de que, ajudando o aluno a se acalmar e a se concentrar, facilitase o processo de ensino-aprendizagem. A crença é, portanto, que, quando se trata o aluno, figura na qual, supostamente, reside o problema, os objetivos da escola podem ser concretizados.

Não podemos esquecer que a procura pela medicação se realiza em um momento em que os avanços na área farmacêutica, assim como sua necessidade em produzir mercado, são notórios. Sobre isso, Faraone, Barcala, Bianchi e Torricelli explicam que a saúde, e aqui incluímos a saúde mental, integra "la esfera economico-mercantil en la medida en que se há convertido en un objeto de consumo, en un producto que pode ser fabricado por los laboratórios farmacéuticos y consumido por los enfermos reales o posibles" (2009, p. 8). Nesse contexto, conforme assinala Rodrigues, não é exagero considerar que encontramos remédio para tudo, até para o que não existe. "Temos medicações para tratar ejaculação precoce, impotência, depressão, mau-humor, preguiça crônica, distrabilidade, etc. Parece não haver limites" (2003, p. 5).

A medicação tornou-se, literalmente, o remédio para os problemas de toda ordem, seja de ordem médica ou não, e dela nos utilizamos para compreender e solucionar os conflitos produzidos socialmente, tentando, mediante intervenções voltadas para a criança em particular, resoluções para os problemas da educação, da saúde, da família e da relação entre adultos e crianças em geral. Assim, muitas condutas, como a indisciplina ou a não aprendizagem, que, a nosso juízo, evidenciam os precários resultados do sistema educacional e escolar em nossos dias, possuem uma classificação e são diagnosticadas segundo os critérios do DSM-IV ou do CID-10. Ressaltamos que o CAPSi não está excluído desse processo, ao contrário, participa de forma ativa: constitui a via para a obtenção desse diagnóstico e, em consequência, da medicação.

\section{No CAPSi: percalços na consolidação do trabalho coletivo}

Tendo como referência as informações coletadas nesta pesquisa, uma constatação salta aos olhos: um dos pilares das novas práticas de cuidado em saúde mental, ou seja, o trabalho desenvolvido por equipe multiprofissional, não está sendo desenvolvido. O CAPSi estudado apresenta dificuldades em organizar um trabalho coletivo tanto internamente, entre os membros da própria equipe, quanto externamente, em articulação com outros serviços de saúde e com a comunidade. As declarações das profissionais mostram que elas estão inseridas no serviço, porém desconhecem a função do dispositivo. Muitas relacionaram o CAPSi a um ambulatório ${ }^{9}$ : Não. De jeito nenhum. Oh, eu sabia na parte teórica, mas a prática... Então, assim, eu só fui amadurecer a ideia de CAPS alguns anos atrás, porque tem CAPS que tem nome de CAPS, mas funciona como ambulatório (psiquiatra).

Esse desconhecimento nos remete à formação dos profissionais da área de saúde mental, que, em um contexto sociocultural cujo valor central é o indivíduo, dificilmente privilegia uma visão do todo ou uma compreensão do objeto da profissão como constituído dentro de um emaranhado de relações produzidas socialmente. Nas palavras de Scarcelli:

Os cursos universitários, no geral, inclusive os de Psicologia e Medicina, não enfatizam a produção de um novo conhecimento na direção de práticas antimanicomiais. Mas, independentemente de estarem ou não voltados para esse tipo de prática, muitos profissionais saem de seus cursos sem se 
sentirem capazes para desempenhar sua nova função, por não terem se apropriado de alguma técnica orientadora de suas ações (1999, p. 308)

Sem uma técnica norteadora, cada profissional transpõe para o âmbito público aquilo que a formação acadêmica e a cultura existente em torno da profissão estabelecem como padrão hegemônico, ou seja, o atendimento clínico individual. Tal prática gera, não raro, um trabalho fragmentado e uma demanda inadequada para o serviço, descaracterizando a função para a qual se destina o dispositivo. Esse posicionamento é ratificado ao investigarmos o cotidiano do serviço, que revela a inexistência de um trabalho realizado em equipe e uma organização cujas características evidenciam uma forma de atendimento ambulatorial.

A entrada no serviço tem início com a triagem, realizada pela enfermeira ou pela assistente social. Em seguida, dependendo do caso, é agendada uma avaliação com um dos profissionais: - Aí, ela tria, aí, a gente tinha que estar discutindo, mas, aí assim, elas veem o que a criança precisa e marcam a primeira consulta (psiquiatra). É comum que a primeira consulta seja agendada para uma das especialidades médicas. Tal conduta é explicada pela assistente social da seguinte forma:

Na verdade, por enquanto, ainda está tudo tumultuado... Então, os estudos de caso são feitos esporadicamente, casos mais graves, a gente já faz triagem e já marca o atendimento, casos graves, eu digo assim, tentativa de suicídio, pacientes em crise, daí a gente já chega a marcar atendimento com a psiquiatra. Na dúvida, a gente tenta deixar para estudo de caso. Na dificuldade da equipe conseguir dar prosseguimento ao estudo de caso, muitas vezes, acaba que a gente agenda para a neurologista ou a psiquiatra avaliar para poder dar atendimento, mas, quanto a isso, a gente é bem desorganizada ainda.
Esses relatos, assim como alguns estudos pesquisados sobre o trabalho interdisciplinar na saúde e o trabalho em rede na saúde mental (Bezerra \& Dimenstein, 2008; Scherer, Pires, \& Schwartz, 2009; Ronchi \& Avelar, 2010), revelam as dificuldades encontradas no processo de consolidação de um trabalho coletivo e, portanto, na construção do novo modelo de atenção em saúde mental. A razão disso, provavelmente, está na dinâmica social que valoriza o indivíduo, cujas implicações podem ser observadas nas diferentes esferas sociais. Dessa forma, há que se questionar a aplicabilidade de uma política que tem como sustentáculo o trabalho coletivo em uma sociedade voltada para os interesses individuais. Acreditamos que a dificuldade em consolidar práticas coletivas no serviço público possa ser entendida por esse paradoxo. Afinal, como atender a essa proposta se vivemos sob uma cultura individualista? Com esse questionamento, não estamos defendendo a permanência dessa situação, mas apontando que essas dificuldades, de fato, existem e devem ser conhecidas e enfrentadas por aqueles que, por opção ou não, atuam na área da saúde pública e na da saúde mental.

No cotidiano do CAPSi, uma das consequências decorrente das dificuldades em efetivar o trabalho de uma forma coletiva recai sobre a formulação do diagnóstico, que, em geral, é definido a critério da médica: - Bom, eu não sei, assim, como se chega, porque, na verdade, eu nunca diagnostiquei: 'olha, é isso ou aquilo'; quem diagnostica mesmo são as médicas, elas que fazem (psicóloga). A assistente social, por sua vez, aponta o diagnóstico como uma tarefa da médica, por não se sentir capacitada para tal: - Deveria estar acontecendo mais o estudo de caso, mas o diagnóstico mesmo, que eu vejo que é feito, é a doutora que faz. Exclusivamente ela. Não vejo assim, psicólogo, ninguém chegar a um diagnóstico, eu não me vejo capaz, sabe?

Sobre isso, Scarcelli pontua que "a sensação 
Para Scarcelli, na tentativa de sanar os conflitos decorrentes do trabalho interdisciplinar, a equipe pode desenvolver suas intervenções de duas formas: ou abandonando "as próprias concepções, abrindo mão da especificidade em função do grupo", ou buscando "a prevalência de um determinado ponto de vista, o que culmina na incomunicabilidade e impossibilidade de convivência para um projeto comum"

(1999, p. 311$)$.

10 Destacamos o Movimento Nacional dos Familiares dos Usuários e a Consulta Nacional pela Saúde Mental, na Itália, (Goulart, 2008) e o Movimento dos Trabalhadores em Saúde Mental, no Brasil (Amarante, 1995).

11 Movimento que emergiu entre as décadas de 70 e 80 , seu objetivo era "constituir-se enquanto um saber contra-hegemônico e crítico ao modelo dominante de atenção à saúde e produzir uma reforma nas políticas e práticas de saúde que vigoravam no Brasil de forma a possibilitar a obtenção efetiva da saúde por toda a população" (Dimenstein, 1998, p. 59). de 'não saber' faz parte do cotidiano dos trabalhadores" (1999, p.303). Essa concepção também é defendida por Macedo ao afirmar que, na área da saúde, "o desafio atual do trabalho multiprofissional é produzir um novo saber" (2007, p. 33), processo que, muitas vezes, gera conflitos.

Para Scarcelli, na tentativa de sanar os conflitos decorrentes do trabalho interdisciplinar, a equipe pode desenvolver suas intervenções de duas formas: ou abandonando "as próprias concepções, abrindo mão da especificidade em função do grupo", ou buscando "a prevalência de um determinado ponto de vista, o que culmina na incomunicabilidade e impossibilidade de convivência para um projeto comum" (1999, p. 311). No segundo caso, a autora salienta que a prevalência do saber médico ganha destaque, porque, embora seja alvo de críticas por parte dos demais profissionais, "parece apresentarse como dono de algumas certezas, que muitas vezes chegam a ser estruturantes para a própria equipe" (Scarcelli, 1999, pp. 312-313).

Com frequência, como observamos em nosso estudo, as limitações no desenvolvimento do trabalho interdisciplinar traz implicações, como conta a assistente social: - E muitas vezes a gente acaba atendendo muitos casos que não são casos CAPSi mesmo, que eu vejo que é uma falha assim do serviço. E são muitos casos que não deveriam estar aqui.

Além das dificuldades em organizar o trabalho internamente, os profissionais entrevistados constataram que a organização da rede de cuidados, cuja responsabilidade também compete ao CAPSi, não é efetiva: Não tem assim uma rede, né?" (psiquiatra). - Nós temos que reestruturar e trabalhar melhor junto com a base, com a atenção básica... Acho que nós temos que melhorar isso (enfermeira).
Todos esses entraves relacionados à dinâmica de trabalho do CAPSi estudado mostram como suas ações encontram-se isoladas não só dos demais setores que compõem a rede de atenção mas também dos munícipes, porque, embora o funcionamento do dispositivo seja distante do que é apregoado pela Política Nacional de Saúde Mental, não existe uma cobrança da população por mudanças.

\section{O controle social}

Os encaminhamentos inadequados realizados pela escola e a aceitação dos familiares, à medida que buscam e recebem um atendimento médico no serviço, demonstram o desconhecimento popular no que diz respeito ao dispositivo. Isso nos chama a atenção, particularmente, devido ao fato de o processo de reforma psiquiátrica, tanto no Brasil quanto em outros países, ter sido impulsionado pelos movimentos sociais ${ }^{10}$.

No Brasil, na VIII Conferência Nacional de Saúde realizada em Brasília, em 1986, foram definidas e aprovadas propostas que já vinham sendo discutidas pelo Movimento Sanitário ${ }^{11}$ em décadas anteriores. Uma dessas propostas, referente ao exercício do direito à saúde, e que vigora ainda hoje, é a garantia da "participação popular no controle social dos serviços de saúde" (Brasil, 1986, p. 5). Entendemos que o exercício desse controle só se torna possível se houver um conhecimento por parte dos demais setores da sociedade e da população em geral acerca da função e dos objetivos dos aparatos de saúde, conhecimento esse que percebemos, pelos dados coletados, não existir sequer entre os próprios profissionais e setores da área, como enfatiza a coordenadora do CAPSi: - O próprio Saúde da Família, eles têm uma visão distorcida de nós.

A incompreensão de grande parte da população acerca da função do CAPSi dificulta a fiscalização e as cobranças a fim de assegurar a funcionalidade adequada do serviço. Sem 
Souza pontua que, na atualidade, as dificuldades escolares manifestadas pelo aluno não questionam "a escola, o método, as condições de aprendizagem e de escolarização, mas sim, buscam na criança, em áreas do seu cérebro, em seu comportamento manifesto, as causas das dificuldades de leitura, escrita, cálculo e

acompanhamento dos conteúdos escolares (2010, p. 63)".

12 Dados extraídos das informações médicas contidas nos prontuários examinados. o engajamento popular na construção e na implementação das políticas públicas no setor, os CAPSi são criados como entidades a-históricas, e, uma vez apartados de sua história, têm o seu nome mudado, mas não a sua prática, que permanece como antes, desviando-se, dessa forma, do cumprimento de sua própria função.

\section{Considerações finais}

Os resultados desta investigação possibilitaram-nos constatar os descaminhos nas áreas da educação e da saúde sobre os quais lançamos nossas reflexões. Designamos como descaminho o desvio de função praticado tanto pela escola quanto pelo CAPSi. Na escola, observamos que muitos encaminhamentos ao CAPSi são realizados porque a escola, em geral, não tem conseguido obter êxito na execução de suas funções. Se o aluno tem dificuldades de aprender ou não se comporta durante as aulas, tal fato não é entendido pela maioria das pessoas envolvidas no processo de ensino como um possível problema gerado no âmbito institucional ou social para além do indivíduo. Via de regra, o problema é atribuído ao aluno e, como tal, é encaminhado.

Sobre esse tema, Souza pontua que, na atualidade, as dificuldades escolares manifestadas pelo aluno não questionam "a escola, o método, as condições de aprendizagem e de escolarização, mas sim, buscam na criança, em áreas do seu cérebro, em seu comportamento manifesto, as causas das dificuldades de leitura, escrita, cálculo e acompanhamento dos conteúdos escolares “(2010, p. 63).

Dados obtidos em nosso estudo revelam várias situações que corroboram essa ideia e que apontam o universo escolar como um espaço desfavorável à apropriação do conhecimento. E, embora tal panorama tenha sido descrito pelos próprios entrevistados, pais e profissionais da educação procuram uma solução fora da escola: o remédio, uma solução mais rápida, tal como exige a acelerada sociedade em que vivemos, que, se não resolve os problemas referentes ao âmbito educacional, ao menos ajuda a tornálos menos perceptíveis.

O CAPSi insere-se, nesse contexto, como a via para a obtenção de medicamento. Encaminhadas pela escola, fundamentalmente sob a alegação de que apresentam sintomas de patologias, como transtorno de déficit de atenção e hiperatividade - TDAH - ou distúrbios de conduta, essas crianças são acolhidas e, muitas vezes, atendidas no CAPSi como portadoras desses ou de outros transtornos, e passam por consultas médicas, realizam exames, como eletroencefalogramas e tomografias, que culminam, não raro, na prescrição de medicamentos. Lembramos que, segundo Elia (2005), em texto divulgado pelo Ministério da Saúde sobre a política que orienta esse setor, toda demanda deve ser acolhida, o que não implica necessariamente atendimento. Uma alternativa pode ser, por exemplo, a desconstrução da demanda.

A forma como vem ocorrendo a parceria entre a escola e o CAPSi tem gerado, não raro, gastos desnecessários na área da saúde, como a disponibilização de funcionários e a realização de uma gama de procedimentos, tais como os exames já mencionados. A título de ilustração, citamos os resultados de um levantamento acerca dos exames solicitados aos usuários que iniciaram atendimento no CAPSi estudado nesta pesquisa no ano 2010. De um total de 135 prontuários examinados, constatamos que foram solicitados 56 exames, sendo 43 deles correspondentes a eletroencefalogramas, 12, a tomografias (crânio) e um, a raios-X (crânio). Vale ressaltar que em apenas seis deles os resultados apresentaram alterações com algum significado patológico ${ }^{12}$, e dez ainda aguardam os resultados. 
Há que se pensar também sobre os programas de educação inclusiva em implantação no País, porque, se por um lado, tais programas se inserem dentro de uma política cujo objetivo central é garantir o "acesso, a participação e a aprendizagem dos alunos com deficiência, transtornos globais do desenvolvimento e altas habilidades/ superdotação nas escolas regulares" (Brasil, 2007b, p. 8), por outro, notamos a existência de uma escola que sequer consegue garantir a escolarização referente a casos menos complexos.

O processo de medicalização dos problemas escolares, observado no CAPSi estudado, evidenciou que a dinâmica do serviço apresenta dificuldades em concretizar as diretrizes estabelecidas para essa nova modalidade de atendimento à saúde mental, previstas na Portaria GM no 336 (Brasil, 2002b) e em publicações elaboradas pelo Ministério da Saúde (Brasil, 2004, 2005). Em nosso estudo, constatamos que o trabalho em equipe, assim como o trabalho em rede, pilares desse modelo de atenção, não têm sido efetivos, e o atendimento permanece sendo realizado de forma ambulatorial, situação igualmente evidenciada em pesquisas sobre dispositivos CAPS de outros Estados brasileiros (Bezerra \& Dimenstein, 2008; Ronchi \& Avellar, 2010).

Entendemos que as dificuldades envolvidas no processo de consolidação de um trabalho coletivo em saúde mental relacionam-se à contradição de ter que implementá-lo em uma sociedade cujos valores se centram no indivíduo, na competição, na liberdade e no consumo. Além disso, a participação popular, fundamental para salvaguardar o cumprimento das funções dessas instituições, não consegue nem é estimulada a se concretizar.

Outra questão suscitada pelos dados obtidos nesta pesquisa, mas que extrapola os objetivos que, aqui, se propõem, refere-se às incertezas que envolvem o significado da infância na contemporaneidade, tema que vem sendo estudado por outros autores, como Postman (2005), por exemplo. As principais queixas relatadas por pais e profissionais da educação relacionaram-se aos comportamentos indesejados no meio escolar, como agressões, dificuldades de aprendizagem e desinteresse pelos estudos. Tal cenário permite-nos avaliar que, à medida que a criança aparece por meio de manifestações diferentes das idealizadas, ela se torna um estorvo com o qual não estamos sabendo lidar e para o qual buscamos formas de silenciar, controlar ou ocultar, lembrando que o remédio, na atualidade, é considerado maneira eficiente de responder a essa necessidade. Dessa forma, acreditamos que essas incertezas também repercutem na forma de cuidado prestada pelas instituições destinadas ao público infantil.

Não há dúvidas de que, historicamente, o CAPSi representa um avanço com relação ao atendimento de crianças e adolescentes acometidos por transtornos mentais, já que, em tempos anteriores, a forma de cuidado a esse público, quando existia, era o tratamento asilar em hospitais. Todavia o conjunto de informações obtido por meio da investigação do cotidiano do CAPSi escolhido como objeto de estudo revelou quão distante o funcionamento desse dispositivo está do que é apregoado pelas políticas públicas em saúde mental que orientam esse setor.

Frente às dificuldades em realizar o trabalho de forma coletiva, a dinâmica de atendimento do CAPSi estudado restringe-se aos moldes ambulatoriais, implicando uma forma de atenção em que a concepção do transtorno mental e das pessoas por ele acometidas são compreendidas sob um único prisma. Observamos que o ponto de vista que se sobressai e que direciona as decisões pertinentes ao serviço, como o atendimento 
e o tratamento dos usuários, se centra no profissional da Medicina, e, apesar de demonstrarem ciência dessa situação ao relatarem que o diagnóstico é definido quase que exclusivamente pelas médicas, as demais profissionais que integram a equipe técnica, como a assistente social, a enfermeira e a psicóloga, pouco questionam essa prática.

Ressaltamos que a falta de questionamento que envolve essa forma de assistência não ocorre apenas da parte dos profissionais do serviço mas também dos usuários, que, com frequência, procuram o CAPSi com a expectativa de conseguir uma consulta médica, a solicitação de um exame ou a obtenção de uma receita de determinada medicação. Toda essa aceitação revela quão naturalizada está essa prática, o que contribui para que esse modelo de atenção se mantenha como prioritário no campo da saúde mental. Diante do exposto, o percurso das crianças da escola ao CAPSi examinado nesta pesquisa, além de mostrar a disfunção nas áreas da educação e saúde, revela aspectos preocupantes no que tange ao cuidado infantil: a medicalização da infância e a responsabilização da criança pelos problemas sociais, educacionais e familiares.

Além de evidenciar um dos diversos problemas que envolvem a interface entre educação e saúde, a realização deste trabalho possibilitou um repensar da prática estabelecida no intuito de desenvolver intervenções que possam romper a naturalização que permeia a demanda de encaminhamentos de queixas escolares. Nessa perspectiva, uma proposta seria retomar a capacitação já iniciada junto aos setores sociais destinados ao cuidado infanto-juvenil, tornando-a mais sistemática e contínua.

\section{Marina Maria Beltrame}

Mestre em Psicologia pela Universidade Estadual de Maringá, Maringá - PR - Brasil.

E-mail: marimaria11@yahoo.com.br

\section{Maria Lúcia Boarini}

Doutora em Psicologia Escolar pela Universidade de São Paulo e docente da Universidade Estadual de Maringá, Maringá - PR - Brasil.

E-mail: mlboarini@uol.com.br

Endereço para envio de correspondência:

Rua Nassib Haddad, 850, Zona 05. CEP: 87015270. Maringá, PR.

Recebido 06/07/2012, 1a Reformulação 27/01/2013, Aprovado 08/02/2013. 


\section{Referências}

Ajuriaguerra, J. (1980). Manual de psiquiatria infantil. Rio de Janeiro: Masson do Brasil.

Alexander, F. G., \& Selesnick, S. T. (1980). História da psiquiatria: uma avaliação dopensamento e da prática psiquiátrica desde os tempos primitivos até o presente (2a ed.). São Paulo: IBRASA.

Amarante, P. (Coord.). (1995). Loucos pela vida: a trajetória da reforma psiquiátrica no Brasil. Rio de Janeiro: Fiocruz.

Bezerra, E., \& Dimenstein, M. (2008). Os CAPS e o trabalho em rede: tecendo o apoio matricial na atenção básica. Psicologia: Ciência e Profissão, 28(3), 632-645.

Boarini, M. L. (1998). Indisciplina escolar: a queixa da atualidade. Apontamentos/Universidade Estadual de Maringá. Maringá PR: EDUEM.

Boarini, M. L., \& Borges, R. F. (2009). Hiperatividade, higiene mental, psicotrópicos: enigmas da caixa de Pandora. Maringá, PR: EDUEM.

Brasil. (1986). VIII Conferência Nacional de Saúde. Relatório final. Brasília DF. Recuperado em 12 junho, 2009, de http://www. conselho.saude.gov.br/biblioteca/relatorios/relatorio_8.pdf

Brasil. Ministério da Saúde. (1988). Relatório final da Conferência Nacional de Saúde Mental. Brasília, DF: Centro de Documentação do Ministério da Saúde.

Brasil. Ministério da Saúde. (1992). Portaria SAS/MS no 224, de 29 de janeiro de 1992. Recuperado em 10 fevereiro, 2011, de http://www.saude.gov.br

Brasil. Ministério da Saúde. (2002a). Relatório final da III Conferência de Saúde Mental, 11 a 15 de dezembro de 2001. Brasília, DF: Conselho Nacional de Saúde/Ministério da Saúde.

Brasil. Ministério da Saúde. (2002b). Portaria no 336/GM, de 19 de fevereiro de 2002. Recuperado em 29 novembro, 2007, de http:// www.saude.gov.br

Brasil. Ministério da Saúde. Secretaria de Atenção à Saúde. Departamento de Acões Programáticas Estratégicas. (2004). Saude Mental no SUS: os Centros de Atenção Psicossocial. Brasília, DF: Ministério da Saúde.

Brasil. Ministério da Saúde. (2005). Caminhos para uma política de saúde mental infanto- juvenil. Brasília, DF: Ministério da Saúde.

Brasil. Ministério da Saúde. Secretaria de Atenção à Saúde. (2007a). Relatório de gestão 2003-2006: saúde mental no SUS: acesso ao tratamento e mudança do modelo de atenção. Brasília, DF: Ministério da Saúde.

Brasil. Ministério da Educação. Secretaria de Educação Especial. (2007b). Política nacional de educação especial na perspectiva da educação inclusiva. Brasília, DF: Ministério da Educação. Recuperado em 12 setembro, 2009, de http://portal.mec.gov/ seesp/arquivos/pdf/politica.pdf

Caldas, M. (1932). A clínica de euphrenia. Archivos Brasileiros de Hygiene Mental, Ano V, 2, 65-80.

Delgado, P. G. G., Schechtman, A., Weber, R., Amstalden, A. F. Bonavigo, E., Cordeiro, F. \& et al. (2007). Reforma psiquiátrica e política de saúde mental no Brasil. In M. F Mello, A. A. F. Mello \& R. Kohn. (Orgs.). Epidemiologia da saúde mental no Brasil (pp. 39-84). Porto Alegre: Artmed.

Dimenstein, M. D. B. (1998). O psicólogo nas Unidades Básicas de Saúde: desafios para a formação e atuação profissionais. Estudos de Psicologia, 3(1), 53-81.

Elia, L. (2005). A rede de atenção na saúde mental: articulaçõe entre CAPS e ambulatórios In. Brasil, Ministério da Saúde. Caminhos para uma política de saúde mental infanto-juvenil. Brasília, DF: Ministério da Saúde.

Faraone, S., Barcala, A., Bianchi, E., \& Torricelli, F. (2009). La industria farmacéutica en los procesos de medicalización/ medicamentalización en la infancia. Margen, 54, 1-10.

Goulart, M. S. B. (2008). Os 30 anos da "Lei Basaglia": aniversário de uma luta. Mnemosine, 4(1), 2-15.

Guarido, R. (2010). A biologização da vida e algumas implicações do discurso médico sobre a educação. In Conselho Regional de Psicologia de São Paulo \& Grupo Interinstitucional Queixa Escolar (Orgs.). Medicalização de crianças e adolescentes: conflitos silenciados pela redução de questões sociais a doenças de indivíduos (pp. 27-39). São Paulo: Casa do Psicólogo.

Liga Brasileira de Hygiene Mental (1930, março). A hygiene mental no Brasil. Archivos Brasileiros de Hygiene Mental, 3(3).

Macedo, P. C. M. (2007). Desafios atuais no trabalho multiprofissional em saúde. Rev. SBPH, 10(2), 33-41.

Marcondes, D. (1941). A higiene mental escolar por meio da clínica de orientação infantil. Revista de Neurologia e Psiquiatria de São Paulo, 7(6), 251-258.

Mendonça, D. (2006). A higiene mental do escolar: o ardil da ordem Dissertação de mestrado. Universidade Estadual de Maringá, Maringá, PR.

Minayo, M. C. S. (1996). O desafio do conhecimento: pesquisa qualitativa em saúde. (4a ed.) São Paulo-Rio de Janeiro: Hucitec-Abrasco.

Moncorvo Filho, C. A. (1927). Histórico da protecção à infância no Brasil: 1500-1922 (2a ed.). Rio de Janeiro: Empreza Graphica Editora - Paulo/Pongetti \& Cia.

Moro, A. P., Lecuona, O. Z., Álvares, A. G. (1985). Metodologia de la investigación histórica. Playa, Ciudad de Habana: Pueblo y Educación

Organização das Nações Unidas para a Educação, a Ciência e a Cultura. (2010). Monitoramento dos objetivos de educação para todos no Brasil 2010. Brasília, DF: Moderna. Recuperado em 21 fevereiro, 2011, de http://unesco.org/images/0018/00189923 por. pdf

Organização Mundial da Saúde. (1993). Classificação de transtornos mentais e de comportamento da CID-10: descrições clínicas e diretrizes diagnósticas. Porto Alegre: Artes Médicas.

Organização Pan-Americana da Saúde e Organização Mundial da Saúde. (2001). Relatório sobre a saúde no mundo 2001. saúde mental: nova concepção, nova esperança. Genebra, Suíça: Autor.

Patto, M. H. S. (1985). A criança da escola pública: deficiente, diferente ou mal trabalhada? In São Paulo (Estado). Secretaria da Educação. Coordenadoria de Estudos e Normas Pedagógicas. Revendo a proposta de alfabetização. (pp.13-21). São Paulo: SE/CENP.

Patto, M. H. S. (1997). Para uma crítica da razão psicométrica. Revista de Psicologia da USP, 8(1). Recuperado em 21 julho, 2009, de http:// www.scielo.br

Postman, N. (2005). O desaparecimento da infância. Rio de Janeiro: Graphia.

Rodrigues, J. T. (2003). A medicação como única resposta: uma miragem do contemporâneo. Psicologia em Estudo, 8(1). Recuperado em 21 julho, 2009, de http:// www.scielo.br

Ronchi, J. P., \& Avellar, L. Z. (2010). Saúde mental da criança e do adolescente: a experiência do CAPSi da cidade de Vitória-ES Psicologia: Teoria e Prática, 12(1), 71-84.

Scarcelli, I. R. (1999). Trabalhadores em saúde mental na construção de práticas antimanicomiais: a rede substitutiva no município de São Paulo. In M. I. A. Fernandes, M. C. T. Vieira \& M. C. G. Vincentin (Orgs). Tecendo a rede: trajetórias da saúde mental em São Paulo (pp. 297-320). Taubaté, SP: Cabral Editora Universitária.

Scherer, M. D. A., Pires, D., \& Schwartz, Y. (2009). Trabalho coletivo: um desafio para a gestão em saúde. Rev. Saúde Pública, 43(4), 721-725.

Souza, M. P. R. (2010). Retornando à patologia para justificar a não aprendizagem escolar: a medicalização e o diagnóstico de transtornos de aprendizagem em tempos de neoliberalismo. In Conselho Regional de Psicologia de São Paulo \& Grupo Interinstitucional Queixa Escolar (Orgs.). Medicalização de crianças e adolescentes: conflitos silenciados pela redução de questões sociais a doenças de indivíduos (pp. 57-67). São Paulo: Casa do Psicólogo. 